\title{
Influence of glycosylation and oligomerization of vaccinia virus complement control protein on level and pattern of functional activity and immunogenicity
}

\author{
Girish J. Kotwal ${ }^{凶}$ \\ Department of Pharmaceutical Sciences, Sullivan University College of Pharmacy, Louisville, KY, USA \\ $\triangle$ Correspondence: Gkotwal@sullivan.edu \\ Received October 15, 2010 Accepted November 23, 2010
}

\begin{abstract}
Vaccinia virus complement control protein (VCP) is one of the proteins encoded by vaccinia virus to modulate the host inflammatory response. VCP modulates the inflammatory response and protects viral habitat by inhibiting the classical and the alternative pathways of complement activation. The extended structure of VCP, mobility between its sequential domains, charge distribution and type of residues at the binding regions are factors that have been identified to influence its ability to bind to complement proteins. We report that a Lister strain of vaccinia virus encodes a VCP homolog (Lis VCP) that is functional, glycosylated, has two amino acids less than the well-characterized VCP from vaccinia virus WR strain (WR VCP), and the human smallpox inhibitor of complement enzymes (SPICE) from variola virus. The glycosylated VCP of Lister is immunogenic in contrast to the weak immunogenicity of the nonglycosylated VCP. Lis VCP is the only orthopoxviral VCP homolog found to be glycosylated, and we speculate that glycosylation influences its pattern of complement inhibition. We also correlate dimerization of VCP observed only in mammalian and baculovirus expression systems to higher levels of activity than monomers, observed in the yeast expression system.
\end{abstract}

KEYWORDS vaccinia virus, complement, glycosylation, oligomerization, structure-function, immunogenicity

\section{INTRODUCTION}

Vaccinia virus is a member of the Orthopoxvirus family.
Various strains of vaccinia virus were employed as vaccines for human immunization during the World Health Organization smallpox eradication campaign (Fenner et al., 1988; Cieslak et al., 2000; Rosenthal et al., 2001). Among the strains of vaccinia virus used for immunization are the Dryvax (derived from the vaccinia virus Wyeth strain), the modified vaccinia Ankara (MVA), the New York City Board of Health $(\mathrm{NYCBH})$ strain, the EM63 strain, the Temple of Heaven strain, and the Lister strain (Bender et al., 1996; Cieslak et al., 2000; Rosenthal et al., 2001; Wittek, 2006). Generally, these strains of vaccinia virus induced severe adverse effects, though mainly in individuals whose immune system was compromised (Henderson et al., 1999; Ober et al., 2002; Empig et al., 2006; Wittek, 2006). The Lister strain of vaccinia virus elicits a strong immune response (take rate of $94 \%$ ), and was extensively used for immunization in countries such as the UK, Germany, France and South Africa (Rosenthal et al., 2001; Ober et al., 2002; Garcel et al., 2007). Garcel et al. (2009) showed that the traditional Lister smallpox vaccine displayed phenotypic and genotypic diversity.

Poxviruses encode several proteins to escape the host immune response (Kotwal, 2000). One of such proteins is vaccinia virus complement control protein (VCP), which was the first soluble microbial protein found to have structural similarity to the family of human complement control proteins like complement receptor 1 , human $\mathrm{C} 4 \mathrm{~b}$ binding protein ( $\mathrm{C} 4 \mathrm{~b}$ $\mathrm{BP}$ ), factor $\mathrm{H}$ and membrane cofactor protein (MCP) (Kotwal and Moss, 1988). The complement system consists of 30 plasma proteins, and is the first line of defense against microorganisms. On activation of the complement system a cascade of events is triggered that results in the formation of a membrane attack complex or release of chemotactic factors. 
It is tightly regulated by a number of soluble and membrane anchored complement control proteins (Kang et al., 2009). VCP subverts host immune response through its ability to act as a cofactor for the serine protease factor I (Sahu et al., 1998) and to promote the decay of the C3 convertase by binding to $\mathrm{C} 3 \mathrm{~b}$ and $\mathrm{C} 4 \mathrm{~b}$ thus inhibiting both the classical and the alternative pathways of complement activation (McKenzie et al., 1992). In addition, VCP can bind to heparin, a property that enables it to be taken up by heparin sulfate proteoglycans on mast cell granules, promoting a slow release of the protein bound to such granules, and mediates persistence in the tissues (Kotwal et al., 1998b; Reynolds et al., 2000). The heparin binding ability of VCP contributes to inhibition of antibody binding to the heparin sulfate proteoglycans on the surface of endothelial cells (Smith et al., 2000; Al-Mohanna et al., 2001).

Considerable experimental evidence supports the complement regulatory activities of VCP in vivo. For example, in an initial experiment, cowpox virus expressing a VCP homolog, the inflammation modulatory protein (IMP), was injected into the footpads of complement C5-sufficient and -deficient mice and it was found that the inflammation was far more severe in mice that did not have a complete repertoire of the complement components (Miller et al., 1995). This meant that IMP regulated the inflammation, which was complement mediated. When BALB/c mice were injected with the wild type cowpox virus or cowpox virus-lacking IMP, it was found that the latter elicited a greater and uncontrolled inflammatory response, which was characterized by severe ulceration and extensive tissue damage, indicating the modulatory role of IMP (Miller et al., 1997; Kotwal et al., 1998a). The therapeutic potential of VCP-like proteins has been investigated using a number of animal inflammatory disease models for Alzheimer's disease, xenotransplant rejection, head and spinal cord injury, rheumatoid arthritis, etc (Smith and Kotwal, 2001; Anderson et al., 2003; Kahn et al., 2003; Scott et al., 2003; Jha et al., 2005). In all models VCP was found to reduce the inflammatory damage and led to an improved outcome.

The VCP from the Western Reserve (WR) strain of vaccinia virus has been used for much of the research. The open reading frame (ORF) encodes a protein of 244 amino acids with a molecular weight of $26.8 \mathrm{kDa}$. WR VCP possesses no glycosylation, acylation, phosphorylation or membrane attachment sites. Recombinant VCP expressed in the medium by the Pichia pastoris expression system is a predominantly monomeric protein capable of retaining its structural and functional integrity even after exposure to extreme $\mathrm{pH}$, temperature and several freeze-thawing cycles (Smith et al., 2002). VCP was observed to occur as a dimer, when expressed in a natural infection (Kotwal et al., 1990) or in a baculovirus or mammalian expression system (Liszewski et al., 2006). X-ray crystallography revealed an elongated protein structure with well-defined modules (Murthy et al., 2001). Like all the other members of the regulators of complement activation (RCA) superfamily, VCP is composed of four short consensus repeats (SCR) (Morley and Campbell, 1984; Ichinose et al., 1990), also known as sushi domains or complement control protein (CCP) modules (Murthy et al., 2001). Each CCP module is composed of six short antiparallel $\beta$ sheets held together by hydrogen bonds and reinforced by a pair of canonical disulphide bridges formed by four invariant cysteine residues (Norman et al., 1991).

When compared to human complement regulatory proteins, VCP has the highest overall amino acid identity (38\%) to C4b-BP (Kotwal and Moss, 1988; Murthy et al., 2001), but the protein is more similar to MCP at the putative complement binding regions and to CR1 in terms of its binding activities.

The extended structure of VCP, mobility between its sequential CCP domains, charge distribution and type of residues at the binding regions are factors that greatly influence its ability to bind to complement proteins and heparin (Smith et al., 2000; Murthy et al., 2001; Ganesh et al., 2004). In other RCA members, such as MCP, the presence of glycans on the protein significantly influences their biologic activities. For example, an MCP isoform with a larger Oglycosylation domain was found to bind $\mathrm{C} 4 \mathrm{~b}$ more efficiently than the other isoforms, which are smaller and less glycosylated in this region (Liszewski and Atkinson, 1996).

In recent times, there has been a lot of research to develop attenuated, safe and effective virus vaccines against smallpox using known strains of vaccinia virus such as the Lister strain and attenuated Lister strain LC16m8 (Morikawa et al., 2005). Also, there is a search for a more active VCP that has specificity as close as possible to the human smallpox inhibitor of complement enzymes (SPICE) (Rosengard et al., 2002), for use as a therapeutic agent in regulating various complement-mediated inflammatory ailments. A previous report suggested that the Lister strain of vaccinia virus encodes a functional VCP (Lis VCP) with an inferred amino acid sequence that is smaller by two residues compared to the WR VCP and SPICE, has two putative N-glycosylation sites and several other differences (Odunuga et al., 2005). The natural VCP or Lis VCP expressed by infection of African green monkey kidney (BSC-1) cell lines with vaccinia virus WR strain or Lister strain was found to inhibit complementmediated lysis of IgG-sensitized sheep erythrocytes several fold more efficiently than its respective recombinant version expressed in yeast cells (Ghebremariam, 2006). Taken together with earlier studies suggesting that in a natural infection the predominant active VCP that is secreted and shows a higher level of activity than the momoner is a dimer (Kotwal et al., 1990) while the recombinant yeast expressed protein is a monomer (Smith et al., 2002), we now suggest that the dimerization influences the higher level of observed activity of naturally expressed VCP. Here the sequence data of the Lis VCP showing the presence of two glycosylation sites and the presence of oligosaccharide chains on Lis VCP supporting our earlier report by Odunuga et al. (2005) is 
presented. Recently another group (Adamo et al., 2009) also has reported the glycosylation of Lis VCP confirming earlier observation by Odunuga et al. (2005). Adamo et al. (2005) show that the antibody response to Lis VCP in mice is significant in contrast to our finding that it is very difficult to elicit a significant antibody response in rabbits and rodents (Kotwal, unpublished) suggesting that the glycosylation may have an influence on immunogenicity, an observation that is consistent with the findings of Adano et al. and a recent observation by Dowling et al. (2007). Lis VCP glycosylation may influence the pattern of its complement inhibition, as the complement inhibition profile appears to mimic the sigmoidal inhibition curve indicative of a co-operative effect observed in the case of glycoprotein C4b-BP in comparison to the nonglycosylated VCP (Kotwal, 1994). This pattern has also been confirmed by examining the functional data comparing Lis VCP and Copenhagen strain VCP as has been reported by Adamo et al. (2009).

\section{RESULTS AND DISCUSSION}

\section{Lister VCP is smaller by two amino acids, has two putative $\mathrm{N}$-glycosylation sites and differences in its primary sequence}

The ORF of VCP gene was amplified from the genomic DNA of the Lister strain of vaccinia virus and sequenced. Sequence comparison using the NCBI blast search revealed that the ORF shares $97 \%$ and $93 \%$ identities with WR VCP and SPICE respectively (Fig. 1A). The ORF encodes a protein consisting of 242 amino acid residues compared to 244 in both WR VCP and SPICE (Rosengard et al., 2002; Sfyroera et al., 2005; Liszewski et al., 2006). The two missing amino acid residues, Asp and Ala, are located within SCR 1 of the protein and respectively correspond to residues 21 and 22 in WR VCP and SPICE (Fig. 1A). The lack of two amino acids in this region of the protein may not have effects on its interaction with either $\mathrm{C} 3 \mathrm{~b}$ or $\mathrm{C} 4 \mathrm{~b}$ components of the complement since generally SCR 1 has little or no influence on the complement inhibitory activity of VCP (Isaacs et al., 2003). Apart from lacking two residues, there are six differences in the primary sequence compared to WR VCP and 17 compared to SPICE; some of these substitutions could have functional significance (Ganesh et al., 2004; Ghebremariam et al., 2005; Sfyroera et al., 2005). When compared to WR VCP and SPICE only, most of these amino acid differences are found within SCR 2 and SCR 4 of the protein and particularly in the $\mathrm{C} 4 \mathrm{~b}$ binding region. None of the changes appears to be required for heparin binding, except K218 that corresponds to K220 in WR VCP and SPICE (Ganesh et al., 2004). Interestingly, changes at $S 166$ and N218 (G168 and K220 respectively in WR VCP and SPICE) result in the formation of two $\mathrm{N}$-glycosylation motifs/signals of the type N-X-S in Lis VCP (Fig. 1A). Among the poxviral complement inhibitors identified so far, this is the first VCP homolog found to have N-glycosylation motifs. It is notable that all the homologs of VCP compared share $100 \%$ identity in the predicted $\mathrm{C} 3 \mathrm{~b}$ binding region, which overlaps SCR 3 and SCR 4 (Fig. $1 \mathrm{~A}$ ), whereas there are many differences in sequences within the C4b binding region in SCR 2 . Phylogenetic analysis and sequence homology suggest that Lis VCP is more closely related to WR VCP than to SPICE (Fig. 1A and 1B).

\section{Lister VCP is functional}

Naturally expressed VCP proteins secreted into culture media of BSC-1 cells infected with vaccinia virus, Lister or WR strain, were tested for their ability to inhibit lysis of sensitized sheep red blood cells (ssRBCs) (Fig. 2). Even at low amounts, the native proteins were more potent by a factor of at least 20 in inhibiting lysis of ssRBCs than their recombinant yeast-expressed versions (not shown) (Ghebremariam, 2006). Lis-VCP is at least 4-fold less active than WR VCP in this assay (Fig. 2). The ability of naturally expressed VCP to form multimers may contribute to the observed higher complement inhibition activity. A study by Liszewski et al. (2006) provides evidence that VCP expressed in glycosylation competent baculovirus expression system or mammalian expression system has higher propensity to form dimers, and together with our observation, this property appears to enhance their ability to inhibit the complement components. It is notable that the inhibition curve for naturally expressed Lis VCP is near sigmoidal (Fig. 2 ), and similar to that reported earlier for human C4b-BP (Kotwal, 1994), a glycosylated complement control protein to which VCP has the best structural similarity at the amino acid level. The binding of Lis VCP to complement components is cooperative and this interaction may be influenced by the presence of groups such as carbohydrate moieties on the protein.

\section{Lister VCP is glycosylated}

Two N-glycosylation sites of the type N-X-S were identified in the conceptually translated primary sequence of Lis VCP (Fig. 1A). Moreover, irrespective of its fewer amino acid residues, the heterologously expressed Lis VCP was found to run at a slightly slower mobility in sodium dodecyl sulfate polyacrylamide gel electrophoresis (SDS-PAGE) than WR VCP (Fig. $3 A$ ) which was also confirmed by immunobloting (data not shown). The same pattern was observed in the mobilities of Lis VCP and WR VCP obtained from the culture media of BSC-1 cells infected with the viruses (data not shown). To determine whether glycosylation accounted for this lower mobility, the protein was digested with PNGase $F$, an enzyme that releases asparagine-linked oligosaccharides from glycoproteins (Fig. 3B). Similarly, WR VCP was digested with the 


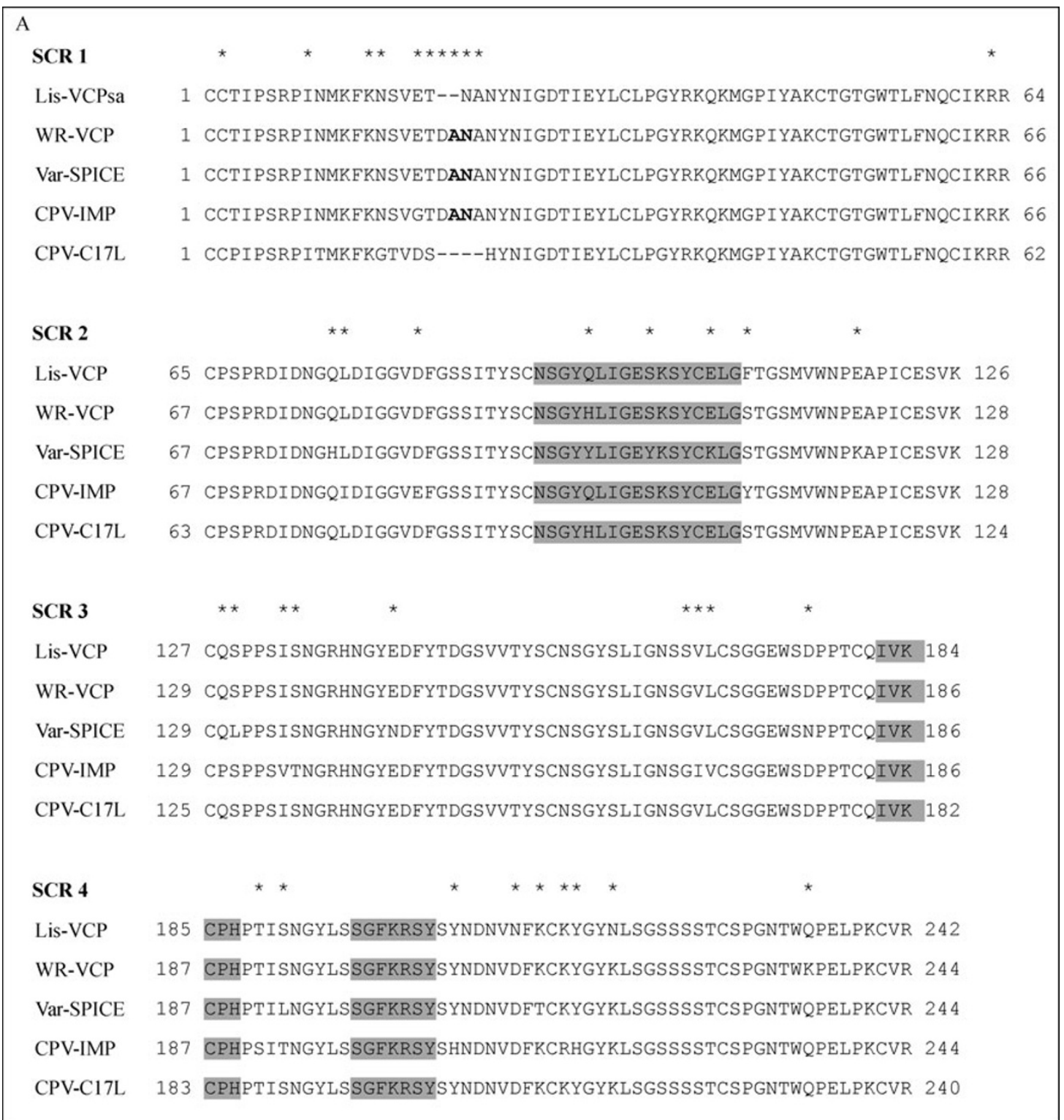

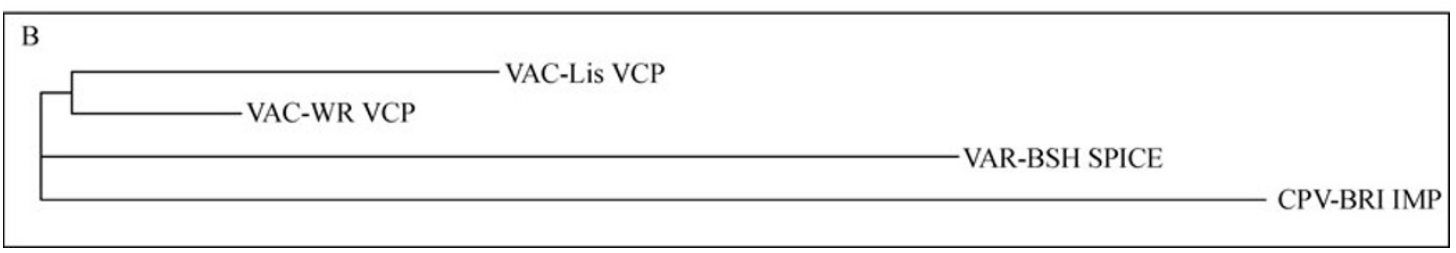

Figure 1. Amino acid sequence alignment of positionally equivalent short consensus repeats (SCRs) and phylogram of various viral complement control proteins. (A) Multiple sequence alignment showing differences in the short consensus repeats (SCRs) of VCP and inflammation modulatory protein (IMP) from Orthopoxviruses. Amino acid sequences of positionally equivalent SCRs from Lis-VCP (VCP from vaccinia virus, Lister strain), WR-VCP (VCP from vaccinia virus, Western Reserve strain, accession P10998), Var-SPICE (SPICE from variola virus, Bangladesh strain, accession AAA69423), CPV-IMP (IMP from cowpox virus, Brighton strain, accession AAM13481), and CPV-C17L (IMP from cowpox virus, Russian isolate from human patient, accession CAA64102) were aligned. Positions where there are differences or missing residues in the sequences are asterisked. Putative binding sites for C4b (SCR 2) and C3b (SCRs 3 and 4), identified based on alanine scanning mutagenesis of the mammalian membrane cofactor protein (MCP) (Liszewski et al., 2000) are shown in gray background. Residues 164 and 218 are putative N-glycosylation sites in Lis-VCP. Residues in bold are missing in Lis-VCP. (B) Phylogram showing evolutionary relationships of various viral complement control proteins. Sequences of VCP from vaccinia virus, Lister and Western Reserve strains (VAC-Lis VCP and VACWR VCP respectively), SPICE from variola virus, Bangladesh strain (VAR-BSH SPICE), and IMP from cowpox virus, Brighton strain (CPV-BRI IMP) were compared using the Clustal W software package (Thompson et al., 1994). VCP, vaccinia virus complement control protein. 


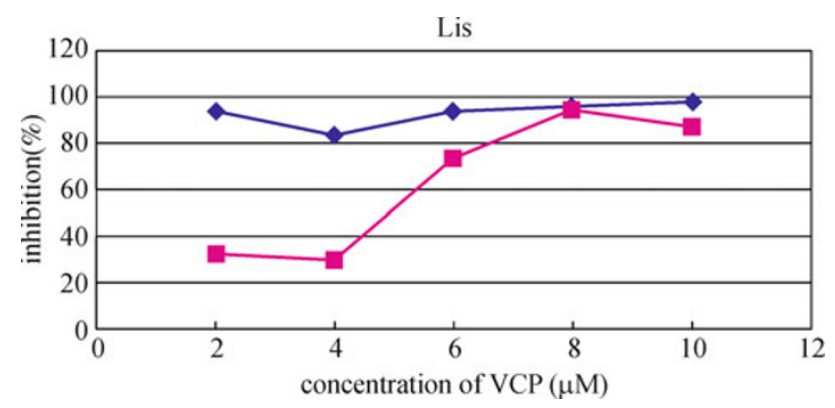

Figure 2. Inhibition of complement-mediated red cell lysis by VCPs. VCPs expressed by natural infection of BSC1 cells with vaccinia virus WR or Lister strain. The sensitized sheep red blood cells (ssRBCs) were pre-incubated with the different concentrations of VCPs for $1 \mathrm{~h}$ in the presence of human serum. Sensitized-red cells directly incubated with the human serum and ssRBCs incubated in the absence of serum were used as positive and negative controls respectively. The diamonds by WR VCP and the squares represent inhibition by Lis VCP. VCP, vaccinia virus complement control protein.

same enzyme (Fig. 3B). Lis VCP digested with PNGase F was found to run at a slightly higher mobility similar to WR VCP (Fig. 3B). WR VCP retained its original mobility before and after digestion with the enzyme (Fig. 3B). These results showed that of the two glycosylation sites introduced by the substitutions, at least one is occupied. Structurally, glycosylation at N164 could disrupt interaction of Lis VCP with C3b due to its proximity to this region and thus may result in a bias toward C4b binding. Similarly, glycosylation at N218 could interfere with heparin binding (Smith et al., 2000; Ganesh et al., 2004) therefore inhibiting binding to the surface of the mast and endothelial cells, and thereby enhance quick clearance of the virus by the host. Both glycosylation sites are sitting on random coils in the predicted secondary structure of the protein and the asparagine residues are well exposed in the modeled three-dimensional structure. In MCP (CD46), while N-glycans on its SCR 2 and SCR 4
(Fig. 4) do not directly participate in ligand binding and only modestly reduce cofactor activity, they significantly influence cytoprotective activity of the protein on the cell surface (Liszewski et al., 1998). A similar mechanism may exist in Lis VCP in which case glycosylation may not impact drastically on its binding to complement components but may have serious implications on the activity of the protein on cell surfaces. Both Lis VCP and C4b-BP have a glycosylation site in a similar position on the primary sequences (Fig. 4). While PNGase-F digestion of Lis-VCP indicates a mobility shift in the Lis VCP protein and evidence of $\mathrm{N}$-glycosylation, the experiments do not demonstrate that both potential $\mathrm{N}$ glycosylation sites are occupied. This will be investigated along with the nature of the $\mathrm{N}$-linked sugars (whether they are biantennary, sialylated, etc.). A future mass spectrometric study of released glycans and naked polypeptide would help to answer all these questions.

\section{MATERIALS AND METHODS}

Growth of Lister vaccinia virus and isolation of Lister viral DNA

Stocks of Lister vaccinia virus were obtained by growing vaccine strain of Lister vaccinia on the chorioallantoic membranes of 9-dayold embryonated hens' eggs using a previously described method (Joklik, 1962; Kotwal and Abrahams, 2004), with some modifications (Stannard et al., 1998). Viral genomic DNA was isolated by phenol: chloroform:isoamyl alcohol (25:24:1) extraction following disruption of poxviral particles in SDS lysis buffer $(50 \mathrm{mM}$ Tris, $700 \mathrm{mM} \mathrm{NaCl}$, $10 \mathrm{mM}$ ethylenediaminetetraacetic acid (EDTA), 1\% SDS, pH 9.5) containing proteinase $\mathrm{K}$, as previously described (Stannard et al., 1998).

\section{Cloning and sequencing of Lis VCP gene}

The ORF of VCP was amplified from genomic DNA isolated from the Lister strain of vaccinia virus, using as forward and reverse primers respectively, the oligonucleotides 5'-GAATTCTGCTGTACTATTCCGTCAC-3' and 5'-GCGGCCGCTTAGCGTACACATTTTGGAAG-3'. The oligonucleotides introduced a 5' EcoRI site and a 3'
A

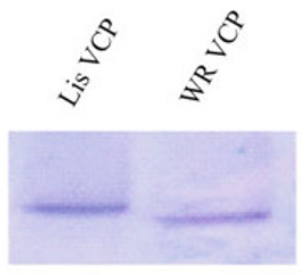

PNGase F
B

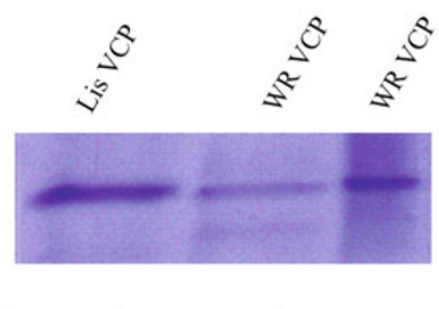

PNGase F

Figure 3. Coomassie-blue stained SDS-PAGE (12\%) analysis following treatment with PNGase F showed that Lister VCP is Nglycosylated. De-glycosylation was done by incubating denatured VCP with peptide-N-glycosidase $F$ (PNGase $F$ ) enzyme at $37^{\circ} \mathrm{C}$ for $3 \mathrm{~h}$. (A) Before digestion with PNGase F. (B) After digestion with PNGase F. SDS-PAGE, sodium dodecyl sulfate polyacrylamide gel electrophoresis. 


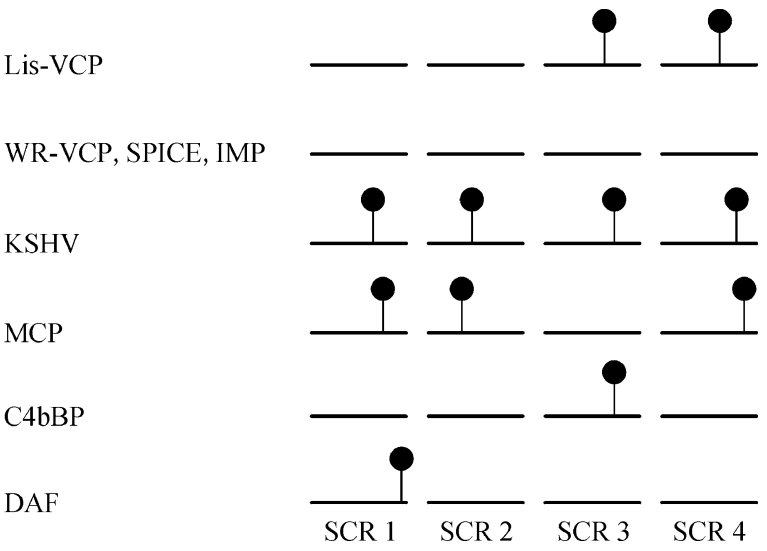

Figure 4. Comparison of $\mathrm{N}$-glycosylation sites within the first four SCRs of complement control proteins. Lis-VCP, VCP from vaccinia virus Lister strain; WR-VCP, VCP from vaccinia virus Western Reserve strain; SPICE from variola virus, Bangladesh strain; IMP, IMP from cowpox virus, Brighton strain; KSHV, Kaposi sarcoma virus ORF4 protein; MCP, human membrane cofactor protein (CD46); C4bBP, human C4b binding-protein; DAF, human decay-accelerating factor (CD55). Horizontal bars and circular arrows represent SCRs and $\mathrm{N}$-glycans respectively. The position and number of the circular arrows indicate the sites and number of N-glycosylation sites in each SCR respectively. The Lister VCP from the LC16m8 sequenced by Morikawa et al. (2005) which has been shown to be glycosylated by Adamo et al. (2009) has only the first of the 2 glycosylation signals. SCR, short consensus repeats.

Notl site respectively, which were used to ligate the amplified DNA fragment into the secretory expression plasmid vector pPIC9 (Invitrogen, CA, USA). Before ligation into EcoRI/Notl digested pPIC9 vector, the PCR fragments were ligated into pGEMT Easy vector (Promega, WI, USA) and digested with the same restriction endonucleases to produce compatible overhangs. pPIC9 plasmids were isolated from several colonies of Escherichia coli cells harboring them and sequencing was done from both ends of the inserted VCP gene using the universal $5^{\prime}$ and $3^{\prime}$ AOX1 primers, 5'-GACTGGTTCCAATTGACAAGC-3' and 5'-GCAAATGGCATTCTGACATCC-3' respectively.

The sequence obtained was compared to the sequences of other VCP homologs available in the databank using the NCBI blast search (http://www.ncbi.nih.gov/BLAST/). The cloning of WR VCP was reported earlier (Smith et al., 2000).

\section{Expression and purification of recombinant VCP}

Pichia pastoris yeast integrants harboring the expression plasmid were selected by both PCR analysis using the universal AOX1 primers, and their ability to grow on medium lacking histidine. For expression, $25 \mathrm{~mL}$ of buffered complex glycerol medium (BMGY) (Invitrogen, CA, USA) was inoculated with a single colony of Pichia integrant and grown at $30^{\circ} \mathrm{C}$ with shaking at 200 rotation $/ \mathrm{min}$ until the culture reached an $\mathrm{OD}_{600}$ of 6 . The cells were harvested and resuspended in $150 \mathrm{~mL}$ of buffered complex methanol medium (BMMY) (Invitrogen, CA, USA) to give an $\mathrm{OD}_{600}$ of 1 . Growth was continued at $30^{\circ} \mathrm{C}$ with vigorous shaking for $4 \mathrm{~d}$, and induction was maintained by addition of methanol to a concentration of $0.5 \%$ daily. Aliquots were taken from the supernatant at regular time intervals and analyzed on $12 \%$ SDS-PAGE to determine the highest expression level and the optimal time post-induction to harvest. Expression was allowed to continue for $96 \mathrm{~h}$ post-induction. The expression medium was centrifuged, the supernatant carefully removed, and further clarified by passing through a $0.22 \mu \mathrm{m}$ syringe filter. The clarified solution was alternately diluted with phosphate-buffered saline (PBS), $\mathrm{pH}$ 7.5, and concentrated using a Millipore Centriprep YM-3 centrifugal filter until an almost clear concentrated protein solution was obtained. Alternatively, the protein was purified by passing through heparin column equilibrated with the binding buffer $(10 \mathrm{mM}$ sodium phosphate, $\mathrm{pH} 7$ ). The column was washed several times with the same buffer and the protein was eluted on a continuous salt gradient ( $10 \mathrm{mM}$ sodium phosphate, $1 \mathrm{M} \mathrm{NaCl}, \mathrm{pH} 7$ ). The eluates were concentrated as described above. Aliquots of the purified protein in both purification procedures were analyzed on $12 \%$ SDSPAGE revealing a major band corresponding to the size of VCP.

\section{Expression of VCP from natural infection}

BSC-1 cell lines were infected with either Lister or vaccinia virus vGK5 strain at a multiplicity of infection of 10 . The cells were incubated for $2 \mathrm{~h}$ in minimal essential medium (MEM) containing $2.5 \%$ fetal calf serum (FCS) and $1 \%$ penicillin/streptomycin/fungizone. The cell monolayer was washed twice with PBS, serum-free MEM was added and the plate was incubated for either $24 \mathrm{~h}$ or $48 \mathrm{~h}$ at $37^{\circ} \mathrm{C}$ and $5 \% \mathrm{CO}_{2}$. The medium was concentrated 200 fold by ultrafiltration using Amicon $2 \mathrm{~mL}$ filters from Millipore and purified as described before using the heparin column (Smith et al., 2000). Quantitation was performed using the BioRad assay and standard VCP at varying concentrations was used to quantitate the VCP. Equal amounts of proteins were then analyzed by hemolysis assay.

\section{Hemolysis assay}

The biologic activities of both the native and recombinant VCPs were determined by testing the ability of the proteins to inhibit complementmediated lysis of ssRBCs using a well-described hemolysis assay (Kotwal et al., 1990). Human serum was the source of complement activity. This assay differentially quantitates the classical pathway of complement activation.

\section{De-glycosylation assay}

Thirty micrograms of VCP was resuspended in $25 \mu \mathrm{L}$ of $50 \mathrm{mM}$ sodium phosphate solution, $\mathrm{pH} 7.5$, after which $2.5 \mu \mathrm{L}$ of denaturation buffer ( $4 \%$ SDS, $5 \% \beta$-mercaptoethanol) was added. The mixture was denatured by incubating at $100^{\circ} \mathrm{C}$ for $10 \mathrm{~min}$ before adding $3 \mu \mathrm{L}$ of peptide-N-glycosidase $\mathrm{F}$ (PNGase $\mathrm{F}$ ) enzyme solution (500 units/ $\mathrm{mL}$ ). The reaction mixture was incubated at $37^{\circ} \mathrm{C}$ for $3 \mathrm{~h}$ to allow deglycosylation to occur, and then stopped by heating to $100^{\circ} \mathrm{C}$ for $5 \mathrm{~min}$. De-glycosylation was assessed by resolving aliquots of the reaction mixture on $12 \%$ SDS-PAGE. 


\section{ACKNOWLEDGEMENTS}

This publication is dedicated to the memory of a distinguished virologist Dr. Frank Fenner (born December 21, 1914) who passed away on November 22, 2010 and made a gigantic contribution to poxvirology and to the global eradication of smallpox as well as control of severe rabbit plague in Australia using myxoma virus (http:// en.wikipedia.org/wiki/Frank_Fenner).

The author most profusely thanks Dr. Odutayo O. Odunuga formerly Claude Leon post doc fellow at University of Cape Town and Yohannes T. Ghebremariam former graduate student and recipient of Poliomyelitis Research Foundation funding at the University of Cape Town for their expert technical contribution, assistance and critical analysis in manuscript preparation. GJK was a Senior International Wellcome Trust Fellow for Biomedical Sciences in South Africa (2001-2006), where some of the work was carried out. This manuscript was only possible due to the reports of Adano et al. (2009) and Garcel et al. (2009) for having confirmed our earlier observation and increasing the level of confidence in our previous data. Thanks are due to Dr. Wolfe Katz of BioVac for providing the South African Lister vaccine.

\section{ABBREVIATIONS}

BMGY, buffered complex glycerol medium; BMMY, buffered complex methanol medium; C4b-BP, C4b binding protein; $\mathrm{CCP}$, complement control protein; IMP, inflammation modulatory protein; Lis-VCP, VCP from vaccinia virus, Lister strain; MCP, membrane cofactor protein; MEM, minimal essential medium; MVA, modified vaccinia ankara; RCA, regulators of complement activation; SCR, short consensus repeats; SDS-PAGE, sodium dodecyl sulfate polyacrylamide gel electrophoresis; SPICE, smallpox inhibitor of complement enzymes; ssRBCS, sensitized sheep red blood cells; VCP, vaccinia virus complement control protein; WR, Western Reserve

\section{REFERENCES}

Adamo, J.E., Meseda, C.A., Weir, J.P., and Merchlinsky, M.J. (2009). Smallpox vaccines induce antibodies to the immunomodulatory, secreted vaccinia virus complement control protein. J Gen Virol 90, 2604-2608.

Al-Mohanna, F., Parhar, R., and Kotwal, G.J. (2001). Vaccinia virus complement control protein is capable of protecting xenoendothelial cells from antibody binding and killing by human complement and cytotoxic cells. Transplantation 71, 796-801.

Anderson, J.B., Smith, S.A., van Wijk, R., Chien, S., and Kotwal, G.J. (2003). Vaccinia virus complement control protein inhibits hyperacute xenorejection in a guinea pig-to-rat heterotopic cervical cardiac xenograft model by blocking both xenoantibody binding and complement pathway activation. Transpl Immunol 11, 129-135.

Bender, B.S., Rowe, C.A., Taylor, S.F., Wyatt, L.S., Moss, B., and Small, P.A. Jr. (1996). Oral immunization with a replicationdeficient recombinant vaccinia virus protects mice against influenza. J Virol 70, 6418-6424.

Cieslak, T.J., Christopher, G.W., Kortepeter, M.G., Rowe, J.R., Pavlin, J.A., Culpepper, R.C., and Eitzen, E.M. Jr. (2000). Immunization against potential biological warfare agents. Clin Infect Dis 30 , 843-850.
Dowling, W., Thompson, E., Badger, C., Mellquist, J.L., Garrison, A. R., Smith, J.M., Paragas, J., Hogan, R.J., and Schmaljohn, C. (2007). Influences of glycosylation on antigenicity, immunogenicity, and protective efficacy of ebola virus GP DNA vaccines. J Virol 81, 1821-1837.

Empig, C., Kenner, J.R., Perret-Gentil, M., Youree, B.E., Bell, E., Chen, A., Gurwith, M., Higgins, K., Lock, M., Rice, A.D., et al. (2006). Highly attenuated smallpox vaccine protects rabbits and mice against pathogenic orthopoxvirus challenge. Vaccine 24 , 3686-3694.

Fenner, F., Henderson, D.A., Arita, I., Jezek, Z., and Ladnyi, I.D. (1988) Smallpox and its eradication. Geneva: World Health Organization

Ganesh, V.K., Smith, S.A., Kotwal, G.J., and Murthy, K.H.M. (2004). Structure of vaccinia complement protein in complex with heparin and potential implications for complement regulation. Proc Natl Acad Sci USA 101, 8924-8929.

Garcel, A., Crance, J.-M., Drillien, R., Garin, D., and Favier, A.-L. (2007). Genomic sequence of a clonal isolate of the vaccinia virus Lister strain employed for smallpox vaccination in France and its comparison to other orthopoxviruses. J Gen Virol 88, 1906-1916

Garcel, A., Perino, J., Crance, J.M., Drillien, R., Garin, D., and Favier, A.L. (2009). Phenotypic and genetic diversity of the traditional Lister smallpox vaccine. Vaccine 27, 708-717.

Ghebremariam, Y.T. (2006). Ph. D. thesis. University of Cape Town, South Africa

Ghebremariam, Y.T., Odunuga, O.O., Janse, K., and Kotwal, G.J. (2005). Humanized recombinant vaccinia virus complement control protein (hrVCP) with three amino acid changes, H98Y, $\mathrm{E} 102 \mathrm{~K}$, and $\mathrm{E} 120 \mathrm{~K}$ creating an additional putative heparin binding site, is 100 -fold more active than rVCP in blocking both classical and alternative complement pathways. Ann N Y Acad Sci 1056, 113-122.

Henderson, D.A., Inglesby, T.V., Bartlett, J.G., Ascher, M.S, Eitzen, E., Jahrling, P.B., et al (1999). Smallpox as a Biological Weapon. JAMA 281, 2127-2137.

Ichinose, A., Bottenus, R.E., and Davie, E.W. (1990). Structure of transglutaminases. J Biol Chem 265, 13411-13414.

Isaacs, S.N., Argyropoulos, E., Sfyroera, G., Mohammad, S., and Lambris, J.D. (2003). Restoration of complement-enhanced neutralization of vaccinia virus virions by novel monoclonal antibodies raised against the vaccinia virus complement control protein. J Virol 77, 8256-8262.

Jha, P., Smith, S.A., Justus, D.E., and Kotwal, G.J. (2005). Vaccinia virus complement control protein ameliorates collagen-induced arthritic mice. Ann N Y Acad Sci 1056, 55-68.

Joklik, W.K. (1962). The purification fo four strains of poxvirus. Virology 18, 9-18.

Kahn, D., Smith, S.A., and Kotwal, G.J. (2003). Dose-dependent inhibition of complement in baboons by vaccinia virus complement control protein: implications in xenotransplantation. Transplant Proc 35, 1606-1608.

Kang, Y.H., Tan, L.A., Carroll, M.V., Gentle, M.E., and Sim, R.B. (2009). Target pattern recognition by complement proteins of the classical and alternative pathways. Adv Exp Med Biol 653, 117-128.

Kotwal, G.J. (1994). Purification of virokines using ultrafiltration. Am Biotechnol Lab 12, 76-77. 
Kotwal, G.J. (2000). Poxviral mimicry of complement and chemokine system components: what's the end game? Immunol Today 21, 242-248.

Kotwal, G.J., and Abrahams, M.R. (2004). Growing poxviruses and determining virus titer. Methods Mol Biol 269, 101-112.

Kotwal, G.J., Isaacs, S.N., McKenzie, R., Frank, M.M., and Moss, B. (1990). Inhibition of the complement cascade by the major secretory protein of vaccinia virus. Science $250,827-830$.

Kotwal, G.J., Miller, C.G., and Justus, D.E. (1998a). The inflammation modulatory protein (IMP) of cowpox virus drastically diminishes the tissue damage by down-regulating cellular infiltration resulting from complement activation. Mol Cell Biochem 185, 39-46.

Kotwal, G.J., and Moss, B. (1988). Vaccinia virus encodes a secretory polypeptide structurally related to complement control proteins. Nature 335, 176-178.

Kotwal, G.J., Reynolds, D., Keeling, K., Howard, J., and Justus, D.E. (1998b) Vaccinia virus complement control protein is a virokine with lysozyme-like heparin-binding activity: possible implications in prolonged evasion of host immune response. In: Proceedings of the 10th International Congress of Immunology. Talwar, G. P., Nath, I., Ganguly, N. K., and Rao, K. V. S. (ed.), New Delhi, 315-320.

Liszewski, M.K., and Atkinson, J.P. (1996). Membrane cofactor protein (MCP; CD46). Isoforms differ in protection against the classical pathway of complement. J Immunol 156, 4415-4421.

Liszewski, M.K., Leung, M., Cui, W., Subramanian, V.B., Parkinson, J., Barlow, P.N., Manchester, M., and Atkinson, J.P. (2000). Dissecting sites important for complement regulatory activity in membrane cofactor protein (MCP; CD46). J Biol Chem 275, 37692-37701.

Liszewski, M.K., Leung, M.K., and Atkinson, J.P. (1998). Membrane cofactor protein: importance of $\mathrm{N}$ - and O-glycosylation for complement regulatory function. J Immunol 161, 3711-3718.

Liszewski, M.K., Leung, M.K., Hauhart, R., Buller, R.M., Bertram, P., Wang, X., Rosengard, A.M., Kotwal, G.J., and Atkinson, J.P. (2006). Structure and regulatory profile of the monkeypox inhibitor of complement: comparison to homologs in vaccinia and variola and evidence for dimer formation. J Immunol 176, 3725-3734.

McKenzie, R., Kotwal, G.J., Moss, B., Hammer, C.H., and Frank, M. M. (1992). Regulation of complement activity by vaccinia virus complement-control protein. J Infect Dis 166, 1245-1250.

Miller, C.G., Justus, D.E., Jayaraman, S., and Kotwal, G.J. (1995). Severe and prolonged inflammatory response to localized cowpox virus infection in footpads of C5-deficient mice: investigation of the role of host complement in poxvirus pathogenesis. Cell Immunol 162, 326-332.

Miller, C.G., Shchelkunov, S.N., and Kotwal, G.J. (1997). The cowpox virus encoded homolog of vaccinia virus is an inflammation modulatory protein. Virology 33, 126-133.

Morikawa, S., Sakiyama, T., Hasegawa, H., Saijo, M., Maeda, A., Kurane, I., Maeno, G., Kimura, J., Hirama, C., Yoshida, T., et al. (2005). An attenuated LC16m8 smallpox vaccine: analysis of fullgenome sequence and induction of immune protection. J Virol 79, 11873-11891.

Morley, B.J., Campbell, R.D.(1984). Internal homologies of the Ba fragment from human complement component Factor $B$, a class III MHC antigen. EMBO J 3,153-157.

Murthy, K.H.M., Smith, S.A., Ganesh, V.K., Judge, K.W., Mullin, N.,
Barlow, P.N., Ogata, C.M., and Kotwal, G.J. (2001). Crystal structure of a complement control protein that regulates both pathways of complement activation and binds heparan sulfate proteoglycans. Cell 104, 301-311.

Norman, D.G., Barlow, P.N., Baron, M., Day, A.J., Sim, R.B., Campbell, I.D.(1991). Three-dimensional structure of a complement control protein module in solution. J Mol Biol 219, 717725.

Ober, B.T., Brühl, P., Schmidt, M., Wieser, V., Gritschenberger, W., Coulibaly, S., Savidis-Dacho, H., Gerencer, M., and Falkner, F.G. (2002). Immunogenicity and safety of defective vaccinia virus lister: comparison with modified vaccinia virus Ankara. J Virol 76, 7713-7723.

Odunuga, O.O., Ghebremariam, Y.T., and Kotwal, G.J. (2005). Lister homologue of vaccinia virus complement control protein is two amino acids shorter, has putative glycosylation sites and other functional and structural differences. FEBS J 272(Supplement 1), 15-16.

Reynolds, D.N., Keeling, K.L., Molestina, R., Srisatjaluk, R., Butterfield, J.H., Ehringer, W., et al. (2000) Heparin binding activity of vaccinia virus complement control protein confers additional properties of uptake by mast cells and attachment to endothelial cells. In: Advances in Animal Virology, Jameel, S., and Lambris, J. D., ed. New York: Oxford \& IBH, 237-342.

Rosengard, A.M., Liu, Y., Nie, Z., and Jimenez, R. (2002). Variola virus immune evasion design: expression of a highly efficient inhibitor of human complement. Proc Natl Acad Sci U S A 99, 8808-8813.

Rosenthal, S.R., Merchlinsky, M., Kleppinger, C., and Goldenthal, K. L. (2001). Developing new smallpox vaccines. Emerg Infect Dis 7, 920-926.

Sahu, A., Isaacs, S.N., Soulika, A.M., and Lambris, J.D. (1998). Interaction of vaccinia virus complement control protein with human complement proteins: factor I-mediated degradation of $\mathrm{C} 3 \mathrm{~b}$ to iC3b1 inactivates the alternative complement pathway. J Immunol 160, 5596-5604.

Scott, M.J., Burch, P.T., Jha, P., Peyton, J.C., Kotwal, G.J., and Cheadle, W.G. (2003). Vaccinia virus complement control protein increases early bacterial clearance during experimental peritonitis. Surg Infect (Larchmt) 4, 317-326.

Sfyroera, G., Katragadda, M., Morikis, D., Isaacs, S.N., and Lambris, J.D. (2005). Electrostatic modeling predicts the activities of orthopoxvirus complement control proteins. J Immunol 174, 2143-2151.

Smith, S.A., and Kotwal, G.J. (2001). Virokines: novel immunomodulatory agents. Expert Opin Biol Ther 1, 343-357.

Smith, S.A., Krishnasamy, G., Murthy, K.H.M., Cooper, A., Bromek, K., Barlow, P.N., and Kotwal, G.J. (2002). Vaccinia virus complement control protein is monomeric, and retains structural and functional integrity after exposure to adverse conditions. Biochim Biophys Acta 1598, 55-64.

Smith, S.A., Mullin, N.P., Parkinson, J., Shchelkunov, S.N., Totmenin, A.V., Loparev, V.N., Srisatjaluk, R., Reynolds, D.N., Keeling, K.L., Justus, D.E., et al. (2000). Conserved surface-exposed K/R-X-K/R motifs and net positive charge on poxvirus complement control proteins serve as putative heparin binding sites and contribute to inhibition of molecular interactions with human endothelial cells: a novel mechanism for evasion of host defense. J Virol 74, 5659-5666. 
Stannard, L.M., Marais, D., Kow, D., and Dumbell, K.R. (1998). Evidence for incomplete replication of a penguin poxvirus in cells of mammalian origin. J Gen Virol 79, 1637-1646.

Thompson, J.D., Higgins, D.G., and Gibson, T.J. (1994). CLUSTAL W: improving the sensitivity of progressive multiple sequence align- ment through sequence weighting, position-specific gap penalties and weight matrix choice. Nucleic Acids Res 22, 4673-4680.

Wittek, R. (2006). Vaccinia immune globulin: current policies, preparedness, and product safety and efficacy. Int $\mathrm{J}$ Infect Dis 10, 193-201. 